\title{
The pollution level of PHC in open waters of Jiaozhou Bay
}

\author{
Dongfang Yang ${ }^{1,4}$, , Xiancheng $\mathrm{Qu}^{1}$, Danfeng Yang $^{2}$, Yu Chen ${ }^{3}$ and Yinjiang \\ Zhang $^{1, b, c}$ \\ ${ }^{1}$ China College of Life Science, Shanghai Ocean University, Shanghai, 201306, China \\ ${ }^{2}$ College of Information Science and Engineering, Fudan University, Shanghai, 200433, China \\ ${ }^{3}$ College of Information, Shanghai Ocean University, Shanghai, 201306, China \\ ${ }^{4}$ North China Sea Environmental Monitoring Center, SOA, Qingdao 266033, China. \\ adfyang_dfyang@126.com; ${ }^{\text {CCorresponding author; }{ }^{c} y j z h a n g @ s h o u . e d u . c n . ~}$
}

Keywords: PHC, Distribution, Source, Pollution level, Open waters, Jiaozhou Bay.

\begin{abstract}
This paper analyzed the content, distribution, source and background level of PHC in Jiaozhou Bay based on investigation data in April, July and October 1986. Results showed that the PHC contents in surface waters ranged from $0.005-0.122 \mathrm{mg} \mathrm{L}^{-1}$, and were meeting Grade I/II (0.05 mg L $\left.{ }^{-1}\right)$ and Grade III (0.30 $\left.\mathrm{mg} \mathrm{L}^{-1}\right)$ in Chinese Sea Water Quality Standard, indicated that the pollution level of PHC in Jiaozhou Bay was slight/moderate in 1986. Stream flow and marine current were the two major PHC sources, whose source strengths were $0.017-0.066 \mathrm{mg} \mathrm{L}^{-1}$ and $0.122 \mathrm{mg} \mathrm{L}^{-1}$, respectively. The pollution of PHC in the open waters, by contrast, was higher than in the stream flow.
\end{abstract}

\section{Introduction}

Along with the rapid development of marine petroleum exploitation, transportation and storage, the marine petroleum pollution has been one of the critical environmental issues on a worldwide scale. In nowadays, many marine bays have been polluted by petroleum hydrocarbon (PHC) [1-11]. Understanding the pollution level, source of PHC in marine bay is essential to marine environmental protection. Jiaozhou Bay is a semi-closed bay located in south of Shandong Peninsula, eastern Chin. The aim of this paper was to analyze the content, distribution, source of PHC, and to provide scientific basis for the research on the source, pollution level and transfer process, and for the sustainable development of study area.

\section{Material and method}

Jiaozhou Bay $\left(120^{\circ} 04^{\prime}-120^{\circ} 23^{\prime} \mathrm{E}, 35^{\circ} 55^{\prime}-36^{\circ} 18^{\prime} \mathrm{N}\right)$ is located in the south of Shandong Province, eastern China (Fig. 1). It is a semi-closed bay with the total area, average water depth and bay mouth width of $446 \mathrm{~km}^{2}, 7 \mathrm{~m}$ and $3 \mathrm{~km}$, respectively. There are more than ten inflow rivers such as Haibo Rriver, Licun Rriver, Dagu Rriver, and Loushan Rriver etc., most of which have seasonal features [12-13]. The data was provided by North China Sea Environmental Monitoring Center. The survey was conducted in April, July and October 1986. Surface water samples in six stations (i.e. 2031, 2032, 2033, 2034, 2035 and 2047) were collected and measured followed by National Specification for Marine Monitoring [14]. 


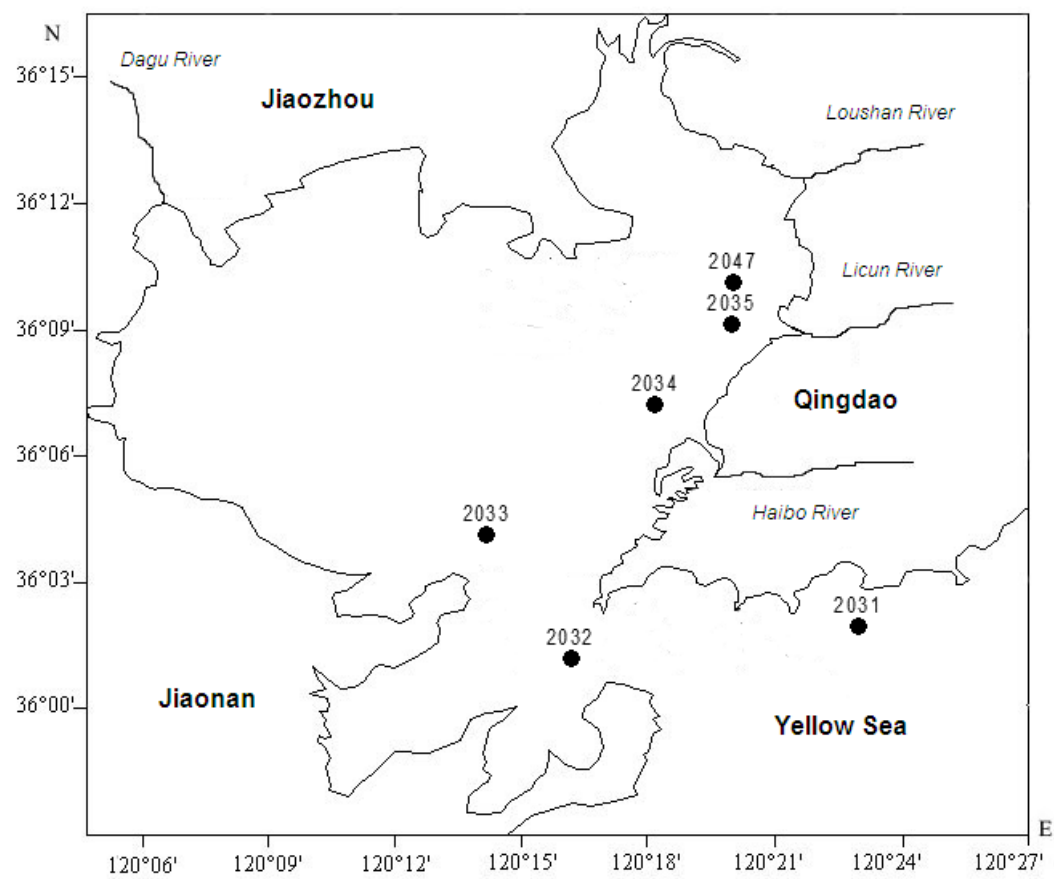

Fig.1 Geographic location and monitoring sites in Jiaozhou Bay

\section{Results and discussion}

Distribution and source of PHC. In April, high value region occurred in Site 2047 in the estuary of Loushan River in the northeast of the bay, and there were a series of parallel lines, which were decreasing from the high value center $\left(0.066 \mathrm{mg} \mathrm{L}^{-1}\right)$ to the bay mouth in the south of the bay $\left(0.005 \mathrm{mg} \mathrm{L}^{-1}\right)$ (Fig. 2). In July, the high value region occurred in Site 2031 in the coastal water in the open waters of the bay, and there were a series of parallel lines, which were decreasing from the high value center $\left(0.122 \mathrm{mg} \mathrm{L}^{-1}\right)$ to the inside of the bay $\left(0.022 \mathrm{mg} \mathrm{L}^{-1}\right)$ (Fig. 3). In October, the high value region occurred in Site 2035 in the estuary of Licun River in the northeast of the bay, and there were a series of parallel lines, which were decreasing from the high value center $(0.017$ $\left.\mathrm{mg} \mathrm{L}^{-1}\right)$ to the bay mouth in the south of the bay $\left(0.005 \mathrm{mg} \mathrm{L}^{-1}\right)$ (Fig. 4). In according to the distribution of PHC, it could be found that there were two major PHC sources in Jiaozhou Bay, i.e., stream flow and marine current.

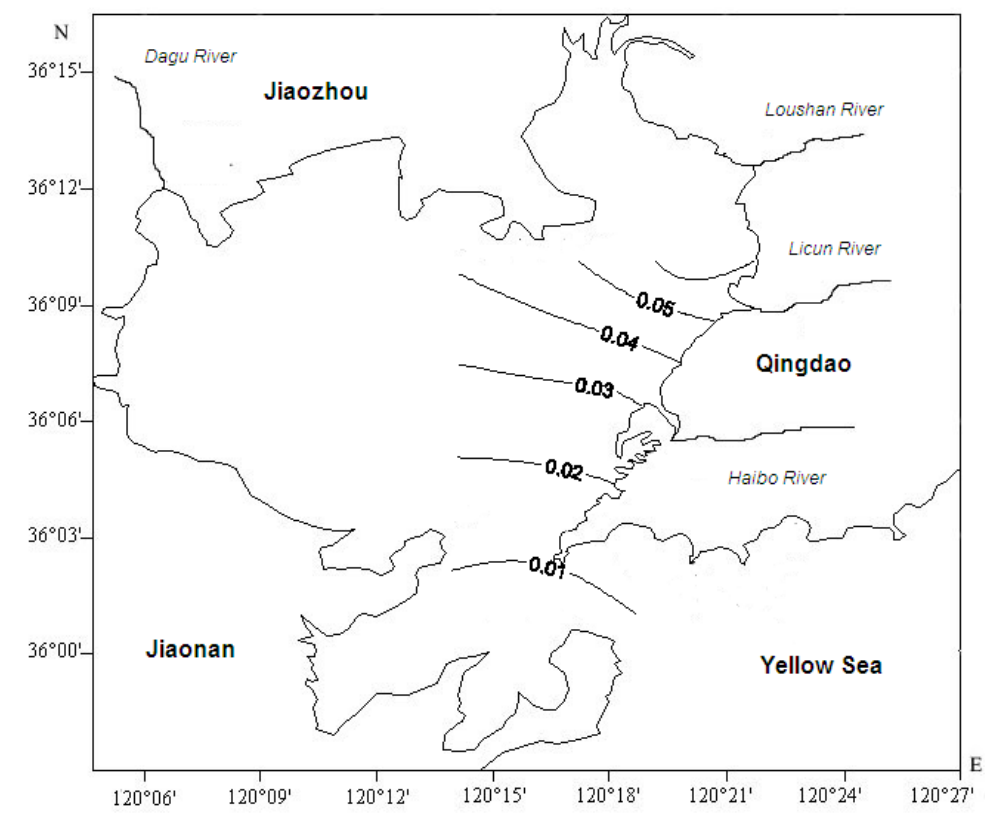

Fig. 2 Distributions of PHC in surface waters in Jiaozhou Bay in April 1986/mg L ${ }^{-1}$ 


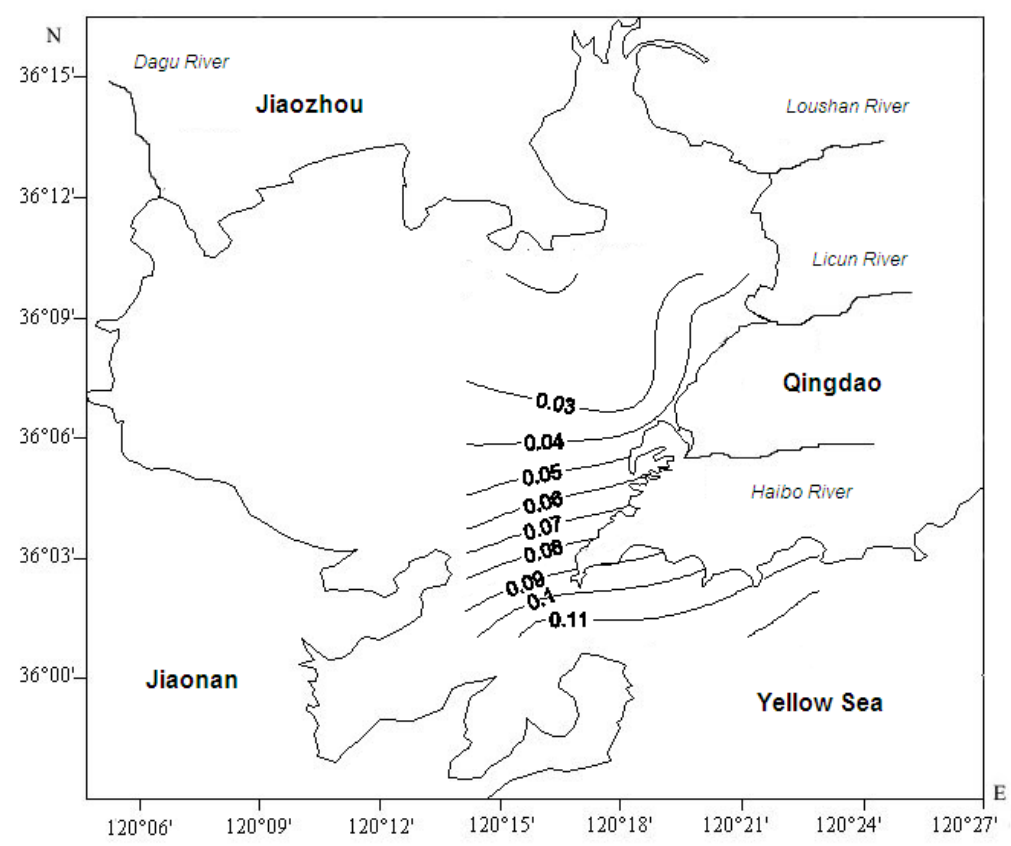

Fig. 3 Distributions of PHC in surface waters in Jiaozhou Bay in July1986/mg L ${ }^{-1}$

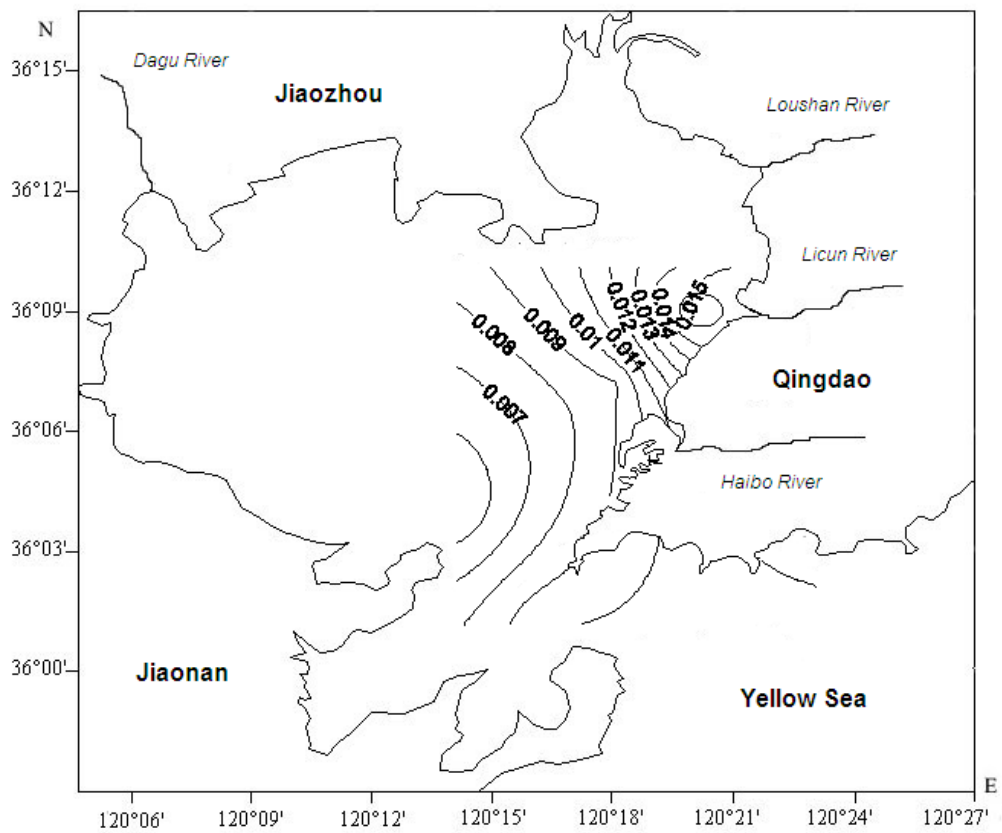

Fig. 4 Distributions of PHC in surface waters in Jiaozhou Bay in October 1986/mg L ${ }^{-1}$

Content and water quality of PHC. The contents of PHC in April, July and October in 1986 in surface waters in Jiaozhou Bay were 0.005-0.066 mg L-1 $0.022-0.122 \mathrm{mg} \mathrm{L}^{-1}$ and $0.005-0.017 \mathrm{mg}$ $\mathrm{L}^{-1}$, respectively (Table 1). In comparison with Grade I/II $\left(0.05 \mathrm{mg} \mathrm{L}^{-1}\right)$ and Grade III $\left(0.30 \mathrm{mg} \mathrm{L}^{-1}\right)$ in Chinese Sea Water Quality Standard (GB 3097-1997) for PHC, the pollution level of PHC in Jiaozhou Bay was slight/moderate in 1986. For spatial variation, PHC contents in the estuaries of the major inflow streams in the northeast of the bay in April 1986 were $0.053-0.064 \mathrm{mg} \mathrm{L}^{-1}$, which were meeting Grade III, while in other regions were Grade I/II. PHC contents in the open waters in July 1986 were $0.022-0.122 \mathrm{mg} \mathrm{L}^{-1}$, which were meeting Grade III, while in other regions were Grade I/II. In October 1986, PHC contents in the whole were meeting Grade I.

Table 1 Contents of PHC in Jiaozhou bay 1986

\begin{tabular}{|c|c|c|c|}
\hline Month & April & July & October \\
\hline Content/mg L ${ }^{-1}$ & $0.005-0.066$ & $0.022-0.122$ & $0.005-0.017$ \\
\hline Grade & I to III & I to III & I \\
\hline
\end{tabular}


Background level of PHC. The major PHC sources in Jiaozhou Bay were stream flow and marine current, whose source strengths were $0.017-0.066 \mathrm{mg} \mathrm{L}^{-1}$ and $0.122 \mathrm{mg} \mathrm{L}^{-1}$, respectively. In generally, the pollution level of PHC in the marine current was even higher than in the stream flow, indicated that back ground pollution level of PHC had reached a certain level in 1986 (Table 2). Hence, PHC in this bay was mainly impacted by marine current. The high values of source strengths of stream flow in April and October were $0.066 \mathrm{mg} \mathrm{L}^{-1}$ and $0.017 \mathrm{mg} \mathrm{L}^{-1}$, yet were both decreasing to $0.005 \mathrm{mg} \mathrm{L}^{-1}$ finally, indicating that the back ground value of PHC in Jiaozhou Bay was $0.005 \mathrm{mg} \mathrm{L}^{-1}$. This back ground value, was stable and independent of the variations of pollution sources, time and source strengths.

Table 2 Source and source strengths of PHC in Jiaozhou bay 1986

\begin{tabular}{|c|c|c|c|}
\hline Source & Loushan River & Licun River & Marine current \\
\hline Strength $/ \mathrm{mg} \mathrm{L}^{-1}$ & 0.066 & 0.017 & 0.122 \\
\hline Grade & III & I & III \\
\hline
\end{tabular}

\section{Conclusions}

The contents of PHC in April, July and October in 1986 in surface waters in Jiaozhou Bay were 0.005-0.066 mg L $\mathrm{mg}^{-1}, 0.022-0.122 \mathrm{mg} \mathrm{L}^{-1}$ and 0.005-0.017 $\mathrm{mg} \mathrm{L}^{-1}$, respectively. The pollution level of PHC in Jiaozhou Bay was slight/moderate in 1986. In according to the horizontal distribution of PHC, it could be found that there were two major PHC sources in Jiaozhou Bay, i.e., stream flow and marine current, whose source strengths were $0.017-0.066 \mathrm{mg} \mathrm{L}^{-1}$ and $0.122 \mathrm{mg} \mathrm{L}^{-1}$, respectively. The back ground value of PHC in Jiaozhou Bay was $0.005 \mathrm{mg} \mathrm{L}^{-1}$, which was stable and independent of the variations of pollution sources, time and source strengths. PHC in this bay was mainly impacted by marine current, and the reduction of environmental in the ocean was essential.

\section{Acknowledgement}

This research was sponsored by Doctoral Degree Construction Library of Guizhou Nationalities University, Education Ministry's New Century Excellent Talents Supporting Plan (NCET-12-0659), the China National Natural Science Foundation (31560107), Major Project of Science and Technology of Guizhou Provincial ([2004]6007-01), Guizhou R\&D Program for Social Development ([2014] 3036) and Research Projects of Guizhou Nationalities University ([2014]02), Research Projects of Guizhou Province Ministry of Education (KY [2014] 266), Research Projects of Guizhou Province Ministry of Science and Technology (LH [2014] 7376).

\section{References}

[1] Yang DF, Zhang YC, Zou J, et al.: Open Journal of Marine Science, vol. 2 (2011), p. 108-112

[2] Yang DF, Sun PY, Chen C, et al.: Coastal Engineering, Vol. 32 (2013), p. 60- 72. (in Chinese)

[3] Yang DF, Sun PY, Ju L, et al.: Applied Mechanics and Materials, Vol.644-650(2014), p. 5312-5315.

[4] Yang DF, Sun PY, Ju L, et al.: Proceedings of the 2015 international symposium on computers and informatics, vol, (2015), p. 2647-2654.

[5] Yang DF, Wang FY, Zhu SX, et al.: Proceedings of the 2015 international symposium on computers and informatics, Vol. (2015), p. 2661-2666.

[6] Yang DF, Sun PY, Ju L, et al.: Proceedings of the 2015 international symposium on computers and informatics, Vol. (2015), p. 2675-2680.

[7] Yang DF, Zhu SX, Wang FY, et al.: 4th International Conference on Energy and Environmental Protection, Vol. (2015), p. 3784-3788. 
[8] Yang DF, Wang FY, Zhu SX, et al.: Advances in Engineering Research, Vol. (2015), p. 431-434.

[9] Yang DF, Wang FY, Zhu SX, et al.: Meterological and Environmental Research, Vol. (2015), p. 31-34.

[10]Yang DF, Zhu SX, Wang FY, et al.: Advances in Engineering Research, Vol. (2016), p. 1351-1355.

[11] Yang DF, Wang FY, Zhu SX, et al.: Meterological and Environmental Research, Vol. (2016), p. 44-47.

[12] Yang DF, Chen Y, Gao ZH, et al.: Chinese Journal of OceanoLogy and LimnoLogy, Vol. 23(2005), p. 72-90.

[13] Yang DF, Wang F, Gao ZH, et al. Marine Science, Vol. 28 (2004), p. 71-74. (in Chinese)

[14]China's State Oceanic Administration: The specification for marine monitoring (Ocean Press, Beijiang 1991), p.1-300. (in Chinese) 